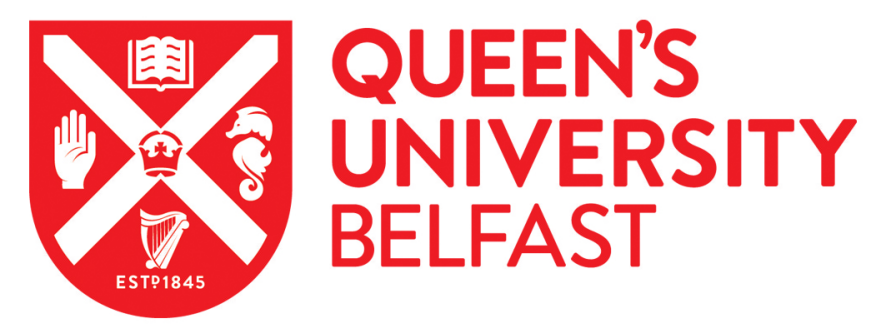

\title{
Detection of soil compaction using seismic surface waves
}

Donohue, S., Dermot, F., \& Donohue, L. A. (2013). Detection of soil compaction using seismic surface waves. Soil and Tillage Research, 128, 54-60. https://doi.org/10.1016/j.still.2012.11.001

\section{Published in:}

Soil and Tillage Research

\section{Document Version:}

Peer reviewed version

\section{Queen's University Belfast - Research Portal:}

Link to publication record in Queen's University Belfast Research Portal

\section{Publisher rights}

Copyright 2012 Elsevier.

This manuscript is distributed under a Creative Commons Attribution-NonCommercial-NoDerivs License

(https://creativecommons.org/licenses/by-nc-nd/4.0/), which permits distribution and reproduction for non-commercial purposes, provided the author and source are cited

\section{General rights}

Copyright for the publications made accessible via the Queen's University Belfast Research Portal is retained by the author(s) and / or other copyright owners and it is a condition of accessing these publications that users recognise and abide by the legal requirements associated with these rights.

\section{Take down policy}

The Research Portal is Queen's institutional repository that provides access to Queen's research output. Every effort has been made to ensure that content in the Research Portal does not infringe any person's rights, or applicable UK laws. If you discover content in the Research Portal that you believe breaches copyright or violates any law, please contact openaccess@qub.ac.uk. 
Title of paper:

Names of authors:

Affiliation of authors:

Corresponding Author:

Dr. Shane Donohue,

School of Planning, Architecture and Civil Engineering,

Queen's University Belfast, David Keir Building, Queen's

University Belfast, BT9 5AG, UK.

\begin{tabular}{|c|c|}
\hline Phone: & $+44(0) 7432131906$ \\
\hline Fax : & $+44(0) 2890974278$ \\
\hline Email: & s.donohue@qub.ac.uk \\
\hline
\end{tabular}




\begin{abstract}
Seismic geophysical methods have rarely been used in precision agriculture, predominantly due to the perception that they are slow and results require a complex evaluation. This paper explores the possibility of using a recently developed surface wave seismic geophysical approach, the Multichannel Analysis of Surface Waves (MASW) method, for assessment of agricultural compaction. This approach has the advantage of being non-intrusive, rapid and is able to produce $2 \mathrm{D}$ ground models with a relatively high density of spatial sampling points. The method, which was tested on a research site in Oakpark, Ireland, detected a significant difference in shear wave velocity between a heavily compacted headland and an uncompacted location. The results from this approach compared favourably with those obtained from measurements of bulk density and cone penetrometers and demonstrate that the MASW approach can distinguish between the extreme states of heavily compacted and uncompacted soil.
\end{abstract}

Keywords: Soil compaction, Seismic, Surface waves, Geophysics, Cone penetrometer, Bulk density 


\section{Introduction}

Assessment of agricultural soil compaction is conventionally performed by soil sampling and laboratory testing or using invasive vertical sensors such as penetrometers (vertical and horizontal) and shear vanes. These approaches may only provide discrete information at individual points on the surface and as such may be inefficient if a dense coverage of data points is required for a complete assessment of compaction.

Seismic field geophysical techniques have rarely been used in precision agriculture, predominantly due to the perception that they are slow and results require a complex evaluation (Petersen et al. 2005; Hoefer and Hartge, 2010). Petersen et al. 2005 for example, suggested that seismic methods are not suitable for measuring on a larger scale. Allred et al. (2008), however, suggested that seismic methods will likely find greater use for agricultural applications in the near future. Although they have rarely been used in field experiments, Lu et al. (2004) have shown a relationship between seismic wave velocity, measured in the laboratory and compaction. In a controlled laboratory setting, they measured an increased compressional (P) wave velocity of a number of soil samples subject to increasing levels of compaction.

Where seismic methods have been considered in field investigations (e.g. Petersen et al. 2005), most authors have only discussed traditional seismic methods, such as $\mathrm{P}$ or $\mathrm{S}$ wave seismic refraction. To the author's knowledge, the use of surface wave seismic methods have not been reported thus far in the agricultural literature. In the civil engineering field, however, surface wave methods such as the Multichannel Analysis of 
Surface Waves (MASW) technique have received considerable attention over recent years, owing to their relatively quick and robust nature and due to their ability to estimate the shear wave velocity $\left(\mathrm{V}_{\mathrm{s}}\right)$, and therefore the shear stiffness, at small strain, of near surface materials. According to elastic theory, the small strain shear modulus, $G_{\max }$, is related to $\mathrm{V}_{\mathrm{s}}$ by the following equation:

$\mathrm{G}_{\max }=\rho \cdot \mathrm{V}_{\mathrm{s}}^{2}$

where $\mathrm{G}_{\max }=$ shear modulus $(\mathrm{Pa}), \mathrm{V}_{\mathrm{s}}=$ shear wave velocity $(\mathrm{m} / \mathrm{s})$ and $\rho=$ density $\left(\mathrm{kg} / \mathrm{m}^{3}\right)$

This paper explores the possibility of using the MASW technique for assessment of agricultural compaction. The results from this approach are compared with those obtained from more conventional measures of soil compaction, such as bulk density and penetrometer resistance. Despite the fact that they operate at different ends of the strain spectrum, the relationship between $\mathrm{V}_{\mathrm{s}}$ or $\mathrm{G}_{\max }$ and penetration resistance from cone penetration tests is actually well established in the field of civil engineering owing to their reliance on similar soil properties. As discussed by Mayne and Rix (1993) and others, $\mathrm{G}_{\max }$ depends on $\mathrm{e}_{0}, \sigma_{\mathrm{v} 0}^{\prime}$ and overconsolidation ratio (OCR), whereas measured cone resistance also depends on $\sigma_{\mathrm{v} 0}^{\prime}$ and OCR. A number of researchers (e.g. Mayne and Rix 1993; Mayne and Rix 1995; Schnaid et al. 2004; Long and Donohue 2010) have observed significant relationships between $V_{s}$ or $G_{\max }$ and $q_{c}$ for a range of materials. 


\section{Surface Waves}

Surface waves, as their name suggests, are seismic waves which propagate along the earth's surface. Their amplitude decreases exponentially with depth and the majority of their energy is contained within one wavelength of the surface. For seismic sources located on the earth's surface, surface waves are significantly more energetic than body waves (P and $\mathrm{S}$ waves) and are almost always easier to detect and acquire. The particular surface wave most commonly utilised for near surface applications are called Raleigh waves, which travel along the earth-air interface with a retrograde elliptical particle motion. The use of surface waves for determining the elastic properties of the subsurface is based on their dispersive nature, i.e. lower frequency (longer wavelength) surface waves generally exhibit higher velocities and are more sensitive to the elastic properties of deeper materials. Higher frequency (shorter wavelength) surface waves are therefore more sensitive to the properties of shallower materials. Therefore by generating a wide range of frequencies, surface wave surveys use dispersion to produce phase velocity and frequency (or wavelength) correlations called dispersion curves. As surface wave phase velocity is strongly related (via Poisson's ratio) to the useful seismic parameter, shear wave velocity $\left(\mathrm{V}_{\mathrm{s}}\right)$, dispersion curves are then subjected to geophysical inversion in order to produce $\mathrm{V}_{\mathrm{s}}$-depth profiles. This process is described in detail by a number of authors (e.g. Aki and Richards 1980; Stokoe et al. 1994; Xia et al. 1999; Socco et al. 2010).

Surface wave methods have become the method of choice for measuring $\mathrm{V}_{\mathrm{s}}$ in the field of civil engineering over the last number of years. Donohue and Long (2008a), for 
example, used the technique for measuring the increase in soil stiffness resultant from a combination of lime treatment and machinery compaction. Although surface waves have been utilised in civil engineering since the 1950's (Jones 1958), the most recent advancement, which analyses multichannel data has only been in use since the late 1990's (e.g. Park et al. 1999; Xia et al. 1999; Donohue and Long 2008b; Foti et al. 2011). Although the method is called a number of acronyms by various practitioners around the world, MASW (Multichannel Analysis of Surface Waves) appears to be the most popular and will be used throughout this paper. The use of multiple receivers with the MASW method (usually 12 to 60 collinear receivers) enable seismic data to be acquired relatively quickly when compared to previous methods used for surface wave acquisition. Another advantage of the MASW approach is the ability of the technique to identify and separate fundamental and higher mode surface waves (surface waves of different frequencies which propagate at similar velocities), which may be present in data, if, for example, a stiffer/higher velocity layer overlies a softer/lower velocity layer or where a significant difference in stiffness/velocity between adjacent layers is present. In these cases both the fundamental and higher modes, if present in the data, should be analysed.

\section{Materials and methods}

\subsection{The site}

The site selected for testing all of these techniques was located at the Teagasc, Oakpark crops research centre, Co. Carlow, Ireland. The soils at the site are derived from compact 
but non-tenaceous, calcareous glacial till, predominantly of limestone origin and of Weichsel Age. The soils of this series consist mainly of well drained podzolics, of loam texture and high base status, and vary in depth from 0.5 to $0.75 \mathrm{~m}$. The soil profile consists of a brown to dark brown surface A horizon, approximately $0.25 \mathrm{~m}$ deep, overlying a yellowish-brown textural B horizon.

The specific site under investigation in this study contained a headland, where a general decrease in yield had been observed during the previous year's harvest. Another area of the site, located $30 \mathrm{~m}$ to the Northeast of the headland was also selected for testing. This area had been subjected to minimal trafficking over the previous number of years and as it was expected to be largely uncompacted, was also selected for comparison. In this paper the headland will henceforth be termed Area 1 and the area expected to be uncompacted will be termed Area 2. The basic physical characteristics of the soils at both locations, which are summarised in Table 1, are very similar.

Bulk density was determined on $98 \mathrm{~cm}^{3}$ cores sampled immediately after the field experiments discussed in the next section. In total, 30 cylinders were sampled, 15 in each area. Cores were sampled from three locations in each area, to a maximum depth of 50 $\mathrm{cm}$. Measurements of gravimetric soil water content were also carried out at each location. All field experiments described in this paper, both conventional and geophysical were conducted at the same time in April 2011. 
Table 1. Basic soil physical characteristics for Areas 1 and 2.

\begin{tabular}{l|lllll}
\hline & & Clay & Silt & Sand & Total \\
& & & & & organic C \\
& & $(\%)$ & $(\%)$ & $(\%)$ & $(\%)$ \\
\hline Area 1 (Headland) & Horiz. A $(0-25 \mathrm{~cm})$ & 18 & 46 & 35 & 2.3 \\
Area 2 & Horiz. B $(25-50 \mathrm{~cm})$ & 25 & 44 & 31 & 0.9 \\
& Horiz. A $(0-25 \mathrm{~cm})$ & 17 & 45 & 38 & 2.3 \\
\hline
\end{tabular}

\subsection{Conventional Assessment of Compaction}

In addition to the measurements of bulk density, described above, cone penetrometer and shear vanes were also used in the experiments, in order to provide comparison with the geophysical approaches for detecting soil compaction.

An ASAE standard (S313.3), 30 degree cone with a base diameter of $12.8 \mathrm{~mm}$ and base area of $130 \mathrm{~mm}^{2}$, was used for these experiments. Twenty seven profiles were acquired in both Area 1 and Area 2, and the results were averaged for each area. All profiles were taken to a depth of $42 \mathrm{~cm}$ at intervals of $4 \mathrm{~cm}$. In order to provide comparison with the 2D geophysical measurements discussed in the next section, nine of the profiles were acquired at $1 \mathrm{~m}$ spacing in a linear profile in Area 1 and a further nine were acquired in an identical setup in Area 2. 


\subsection{MASW data acquisition and inversion parameters}

In order to produce a $\mathrm{V}_{\mathrm{s}}$ profile from an MASW survey the following procedure must be followed (with reference to Figure 1):

(i) Generate vertical ground motions using a vertical impulsive source, e.g. a hammer hitting a metal plate placed on the ground surface.

(ii) Measure these ground motions using 12 - 60 low frequency geophones. The geophones should usually be arranged along a straight line and the impulsive source position should be located at a certain offset from one of the end geophones. An appropriate source offset should be determined during an initial trial and should be selected in order to limit the occurrence of near field effects (non-horizontal propagation of surface waves near the source) on the seismic data. Park et al. (1999) discuss the avoidance of near field effects in detail and Park et al. (2002) suggest optimum field acquisition parameters for MASW surveys used in engineering applications. For shallow soils applications, the acquisition parameters (e.g. geophone spacing, geophone frequency, source type, source location) used in this paper should serve as an initial guide, although it is strongly recommended that a quick field trial is carried out in order to determine the site specific optimum parameters.

(iii) Record the seismic data (Figure 1a) using a conventional seismograph.

(iv) Pick a dispersion curve from the peak amplitude of a phase velocity-frequency spectra of the seismic data (Figure 1b). In this paper, this spectra was generated 
using a wavefield transformation method (McMechan and Yedlin 1981; Park et al., 1998).

(v) Inversion of the picked dispersion curve to produce a 1D subsurface profile of the variation of shear wave velocity with depth (Figure 1c and 1d). Socco et al. (2010) provide an in-depth review of the different ways in which surface wave data can be processed and inverted. If necessary, steps (iv) and (v) may be carried out using a number of readily available commercial software packages.

(vi) Combination of the $1 \mathrm{D}$ inverted profiles to produce a $2 \mathrm{D} \mathrm{V}_{\mathrm{s}}$ profile (see Figure $1 e)$.

The MASW data for the Oakpark test site was recorded using a Geometrics Geode seismograph (with 24 geophones). An initial test profile was conducted at the site, which involved varying the source type and the source/ receiver locations, in order to determine the optimum acquisition parameters. From this initial test it was found that good quality data could be acquired using a 500 g carpentry hammer to generate the surface waves, which were in turn detected by $14 \mathrm{~Hz}$ geophones at $0.12 \mathrm{~m}$ intervals. In total, $26 \mathrm{MASW}$ profiles were acquired, 16 of which were located in Area 1, where soil compaction was assumed to have its greatest effect and the further 10 profiles were located in Area 2. Processing of the MASW data was performed by selecting dispersion curves from a phase velocity-frequency spectra, generated using a wavefield transformation method, as 
in Figure 1b. A normally dispersive phase velocity - frequency relationship was observed for both areas, dominated by the fundamental mode Raleigh wave.

1-D shear wave velocity models were estimated using the least squares approach of Xia et al. (1999). A number of different initial models with different numbers of layers were selected in the initial model in order to test the robustness of the inversion and to determine the model with the lowest misfit. Following the recommendations of Luke and Calderón-Macías (2007) and Cercato (2009), the layer thickness in the model was increased exponentially with depth. This reflects the fact that the resolving power of MASW data decreases with depth. Each inversion was allowed a sufficient number of iterations to converge and was stopped after the overall RMS error was less than $4 \mathrm{~m} / \mathrm{s}$. All of the inversions performed converged rapidly, usually within 4 iterations. It was consistently found that a nine layer initial model produced the lowest RMS error. Additional layers produced similar errors, however these resulted in over-parameterised inversions, as evidenced by artefact low velocity layers, not supported by evidence from the local geology.

\subsection{Data analysis}

An analysis of Variance (ANOVA) was used on the bulk density and moisture content data to test for differences between Area 1 (expected to be heavily compacted) and Area 2 (expected to be relatively uncompacted) for the soil A $(0-25 \mathrm{~cm})$ and B horizons $(25-$ $50 \mathrm{~cm})$. ANOVA was also used on the cone penetration resistance and shear wave 
velocity data to test for differences between Area 1 and Area 2 at each depth level. All variables were checked for normality prior to analysis.

\section{Results and discussion}

\subsection{Conventional measures of compaction}

Gravimetric water content and bulk density data for the A and B horizons of the two study areas are provided in Table 1. Area 1 (headland) exhibited a significantly greater bulk density than Area 2, for the A horizon $(\mathrm{p}<0.01)$, which suggests that it has been compacted quite heavily. For the B horizon, Area 1 exhibited a higher mean bulk density than Area 2, although the difference is not statistically significant. Also, the gravimetric water contents measured for both horizons in Area 1 were lower than in Area 2, although not significantly so.

Table 2. Gravimetric soil water content and bulk density data for Areas 1 and 2.

\begin{tabular}{l|lll}
\hline & \multicolumn{3}{|c}{ Gravimetric soil } \\
& & Bulk density $\left(\mathrm{Mg} / \mathrm{m}^{-3}\right)$ \\
\hline Area 1 (Headland) & Horiz. A $(0-25 \mathrm{~cm})$ & $16.6(2.03)$ & $1.59(0.04)$ \\
& Horiz. B $(25-50 \mathrm{~cm})$ & $20.5(1.15)$ & $1.66(0.08)$ \\
Area 2 & Horiz. A $(0-25 \mathrm{~cm})$ & $18.2(1.65)$ & $1.41(0.03)$ \\
& Horiz. B $(25-50 \mathrm{~cm})$ & $21.2(1.77)$ & $1.59(0.07)$ \\
\hline
\end{tabular}


The numbers presented are mean values and the numbers in brackets are standard deviations.

The mean results for the penetrometer data measured on both areas are illustrated in Figure 2. A significant difference in penetrometer resistance between the two areas was measured for all data points in the A horizon from $6 \mathrm{~cm}$ to $22 \mathrm{~cm}$ depth $(\mathrm{p}<0.01$ for all), with the headland exhibiting a significantly greater penetrometer resistance for this depth interval. Penetrometer resistances measured for the A horizon in Area 1 are on average $45 \%$ greater than those measured for Area 2. Peak penetrometer resistance was measured between 5 and $15 \mathrm{~cm}$ depth. Below $22 \mathrm{~cm}$ depth (B horizon) a difference between the two areas exists, although it is not statistically significant. As discussed above, for comparative purposes nine profiles were acquired at $1 \mathrm{~m}$ spacing in a linear profile on both areas. The results of these individual profiles are illustrated in Figure $3 \mathrm{a}$ and $3 \mathrm{~b}$ for Area 1 and Area 2 respectively. As shown in Figure 3a, higher penetrometer resistances were generally measured between 0 and $5 \mathrm{~m}$ along the linear profile between 6 and $18 \mathrm{~cm}$ depth.

\subsection{MASW}

Each of the individual 1D profiles have been incorporated into $2 \mathrm{D}$ depth sections of $\mathrm{V}_{\mathrm{s}}$ in Figure $4 \mathrm{a}$ and $4 \mathrm{~b}$ for Area 1 and Area 2 respectively. As illustrated, the inverted shear wave velocities vary both vertically and horizontally. For both locations the mean values and standard deviations have been calculated along horizontal lines for each of the layers 
in the upper $0.5 \mathrm{~m}$, distinguished in the shear wave velocity inversion process (Figure 5). A significant difference $(\mathrm{p}<0.01)$ in the shear wave velocity distribution was measured for all of the inverted layers. The velocities measured for the A horizon in Area 1 are on average $21 \%$ greater than those measured for Area 2. At the headland, the MASW method has clearly detected the previously observed compaction in the A horizon, which is indicated by mean shear wave velocities in excess of $120 \mathrm{~m} / \mathrm{s}$. The zone of elevated shear wave velocities observed in Figure 4a, at a distance of 2-5 m, and a depth of 7-21 $\mathrm{cm}$ also corresponds quite closely with the peak penetrometer resistance indicated in Figure 3a. A peak $V_{\mathrm{s}}$ of $137 \mathrm{~m} / \mathrm{s}$ was detected, for the soil A horizon, at $0.18 \mathrm{~m}$ depth (Figure 4a), $3.5 \mathrm{~m}$ from the start of the profile, which again compares well to the cone penetrometer data, where the highest measured resistances were detected on the profile at $3 \mathrm{~m}$ distance. At distances greater than $6 \mathrm{~m}$ along the 2D profile, $\mathrm{V}_{\mathrm{s}}$ decreases slightly, reflecting what appears to be a reduction in compaction. A similar reduction in compaction is also apparent in the cone penetrometer results, between 5 and $8 \mathrm{~m}$ (Figure 3a).

It should be pointed out that for these experiments the maximum frequency picked for construction of the surface wave dispersion curves was between $250 \mathrm{~Hz}$ and $300 \mathrm{~Hz}$, which, given the phase velocities measured, would correspond to a minimum resolvable upper inverted layer of approximately $10 \mathrm{~cm}$. Although the inversion process provides velocities for layers shallower than this $(0.03 \mathrm{~cm}$ and $0.07 \mathrm{~cm}$ in this study), the results for these layers are unlikely to have been accurately resolved. This lack of 
resolution can be seen when the $\mathrm{V}_{\mathrm{s}}$ results (Figure 5) from this depth range are compared to the equivalent penetrometer resistances. As shown in Figure 2, the penetrometer resistances measured at $2 \mathrm{~cm}$ depth for Area 1 are very low relative to deeper measurements. This is in contrast to the $\mathrm{V}_{\mathrm{s}}$ measurements for this depth, where the velocities are similar to those measured below $10 \mathrm{~cm}$ depth. If accurate, higher resolution information is required for the upper $10 \mathrm{~cm}$, higher frequency surface waves will need to be generated, possibly by using an alternative source to that used in this study.

Shear wave velocities measured in Area 1 for the B horizon $(0.25 \mathrm{~m}$ to $0.5 \mathrm{~m}$ depth) are also significantly different to those measured for Area 2, indicating compaction of this layer. As discussed above, a marginally higher (although not statistically significant) bulk density and penetrometer resistance were also detected at the headland for this layer. With increasing depth in the B horizon, the difference in inverted $\mathrm{V}_{\mathrm{s}}$ decreases considerably suggesting a reduction in the effect of compaction with depth.

The relationship between $V_{s}$ and penetrometer resistance is illustrated in Figure 6 . The data presented in this plot is taken from the linear profiles of $\mathrm{V}_{\mathrm{s}}$ and penetrometer resistance, which provides a direct comparison between the two sets of data. Data was only used at the depth levels where data exists for both sets. Although there is some scatter in the data, a linear relationship provides a best fit between the two parameters $\left(\mathrm{r}^{2}\right.$ $=0.66, \mathrm{p}<0.001, \mathrm{n}=48$ ), with high $\mathrm{V}_{\mathrm{s}}$ generally corresponding to high penetrometer resistances. As discussed in Section 1, similar relationships have been observed between $\mathrm{V}_{\mathrm{s}}$ and penetration resistance from civil engineering cone penetration tests for a range of 
subsoils (e.g. Mayne and Rix 1993; Mayne and Rix 1995; Schnaid et al. 2004; Long and Donohue 2010), although a number of these relationships are best fit to a power function. Also, based on these relationships (for subsoil only), $\mathrm{V}_{\mathrm{s}}$ would generally be expected to be higher than that measured here, particularly for the higher penetration resistances measured.

\section{Conclusions}

This paper has explored the possibility of using seismic surface waves as a tool for detecting agricultural compaction in a field environment. The particular surface wave method used, the Multichannel Analysis of Surface Waves (MASW) method, clearly detected a significant difference in shear wave velocity between a compacted headland and an uncompacted area with almost identical soil properties. The results using this approach compared favourably with those obtained from measurements of bulk density and cone penetrometers.

The MASW method has a number of advantages over conventional field measures of compaction such as the non-intrusive nature of the method and the ability to measure a large amount of data, relatively quickly, particularly if a portable system incorporating a land streamer is employed. Also, due to their large amplitude relative to other types of seismic waves, surface waves are less affected by noise than methods incorporating other types of seismic wave. The surface wave approach used in this paper, MASW, also has the ability to identify and separate fundamental and higher mode surface waves, which is 
an advantage over other surface wave techniques. The main limitation of the surface wave approach for detection of compaction is the resolution of the technique at very shallow depths. In order to accurately detect the velocity of the upper $10 \mathrm{~cm}$ (approx.) a suitably high frequency source will have to be used. The small carpentry hammer source used in this study does not generate sufficiently high frequencies to sample this shallow material.

Overall our results show that the MASW approach can distinguish between the extreme states of heavily compacted and uncompacted soil. Further work will have to be completed, however, to explore the sensitivity of the method for measuring smaller changes in compaction than those tested here, before this tool can be utilised practically for quantifying compaction.

\section{Acknowledgements}

The first author was funded by the Environmental Protection Agency (EPA) STRIVE programme throughout this work. The authors would like to thank APEX Geoservices for their considerable assistance and advice. The authors would also like to thank Dr. Romaric Limacher and Nishma Agarwal for their assistance.

\section{References}

Aki, K., Richards, P.G., 1980. Quantitative seismology, W.H. Freeman \& Co. 
Allred, B.J., Groom ,D., Ehsani, M.R., Daniels, J.J., 2008. Resistivity methods, in Allred, B.J., Daniels, J.J., and Ehsani, M.R. (Eds.), Handbook of Agricultural Geophysics, CRC Press, Taylor \& Francis Group, 86-108.

Cercato, M., 2009. Addressing non-uniqueness in linearized multichannel surface wave inversion. Geophysical Prospecting 57, 27-47.

Donohue, S., Long, M., 2008a. Ground improvement assessment of glacial till using shear wave velocity. Proceedings of the 3rd International Conference on Site Characterization ICS'3 : Geotechnical and Geophysical Site Characterization, Taipei, 825-830.

Donohue, S. Long, M., 2008b. Assessment of an MASW approach incorporating discrete particle modeling, Journal of Environmental and Engineering Geophysics, 13 (2), 57 68.

Foti, S., Parolai, S., Albarello, D., Picozzi, M. 2011. Application of Surface-Wave Methods for Seismic Site Characterization. Surveys in Geophysics, 32 (6) 777-825.

Hoefer, G., Hartge, K.H., 2010. Subsoil compaction: cause, impact and prevention, in Soil Engineering, Dedousis, A.P., Bartzanas (eds.). Chapter 9, 121-142.

Jones R.B., 1958. In-situ measurement of the dynamic properties of soil by vibration methods. Geotechnique, 8 (1), 1-21.

Mayne, P.W., Rix, G.J. 1993. $\mathrm{G}_{\max }-\mathrm{q}_{\mathrm{c}}$ relationships for clays, Geotechnical Testing Journal, ASTM, 16 (1): 54 - 60. 
Mayne, P.W., Rix, G.J. 1995. Correlations between cone tip resistance and shear wave velocity in natural clay. Soils and Foundations, 35 (2): $107-110$.

McMechan, G.A., Yedlin, M.J., 1981. Analysis of dispersive waves by wave field transformation. Geophysics, 46, 869-874.

Long, M., Donohue, S. 2010. Characterisation of Norwegian marine clays with combined shear wave velocity and CPTU data. Canadian Geotechnical Journal, 47 (5), 709-718.

Lu, Z., Hickey, C.J., Sabatier, J.M., 2004. Effects of compaction on the acoustic velocity in soils, Soil Science Society of America Journal, 69, 7-16.

Luke, B., Calderón-Macías, C., 2007. Inversion of seismic surface wave data to resolve complex profiles. Journal of Geotechnical and Geoenvironmental Engineering, 133 (2), 155-165.

Park, C.B., Xia, J., Miller, R.D., 1998. Imaging dispersion curves of surface waves on multichannel record, SEG, $68^{\text {th }}$ Annual Meeting, New Orleans, Louisiana, 1377-1380.

Park, C.B., Miller, D.M., Xia, J., 1999. Multichannel Analysis of surface waves, Geophysics, 64 (3), 800-808.

Park, C.B., Miller, R.D., Miura, H., 2002, Optimum field parameters of an MASW survey. $6^{\text {th }}$ International Symposium, Society of Exploration Geophysicists-Japan.

Petersen, H., Fleige, H., Rabbel, W., Horn, R. 2005. Applicability of geophysical prospecting methods for mapping of soil compaction and variability of soil texture on farm land. J. Plant Nutr. Soil Sci, 168, 68-79. 
Schnaid F, Lehane B.M. \& Fahey M. (2004). In-situ test characterisation of unusual geomaterials. In Proceedings of International Conference of Site Characrterisation, Porto, Vol 1 CSC-2 pp 49-74.

Socco, L.V., Foti, S., Boiero, D. 2010. Surface-wave analysis for building near-surface velocity models - Established approaches and new perspectives. Geophysics 75 (5), 75A83-75A102.

Stokoe, K. H., II, Wright, G. W., James, A. B., Jose, M.R., 1994. Characterisation of geotechnical sites by SASW method. Iin Woods, R.D., Ed., Geophysical characterization of sites: Oxford Publ.

Xia, J., Miller, R.D., Park, C.B., 1999. Estimation of near surface shear wave velocity by inversion of Raleigh waves, Geophysics, 64(3), 691-700. 


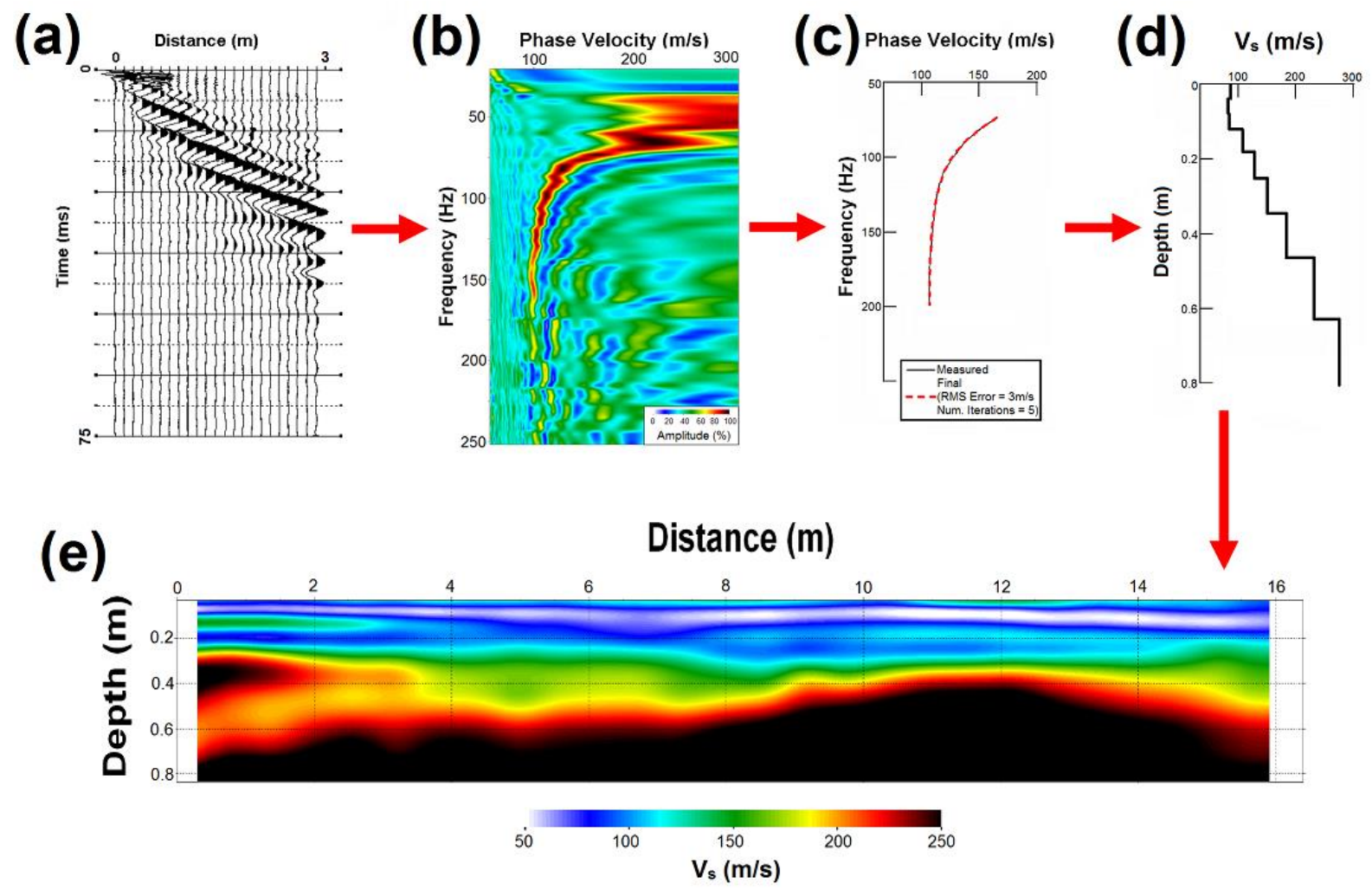

Figure 1 The various stages involved in producing a 2D MASW profile, (a) raw seismic data, (b) dispersion curve image, (c,d) inversion and production of a 1D V $\mathrm{V}_{\mathrm{s}}$-depth profile and (e) 2D Vs image combining inverted 1D Vs profiles 


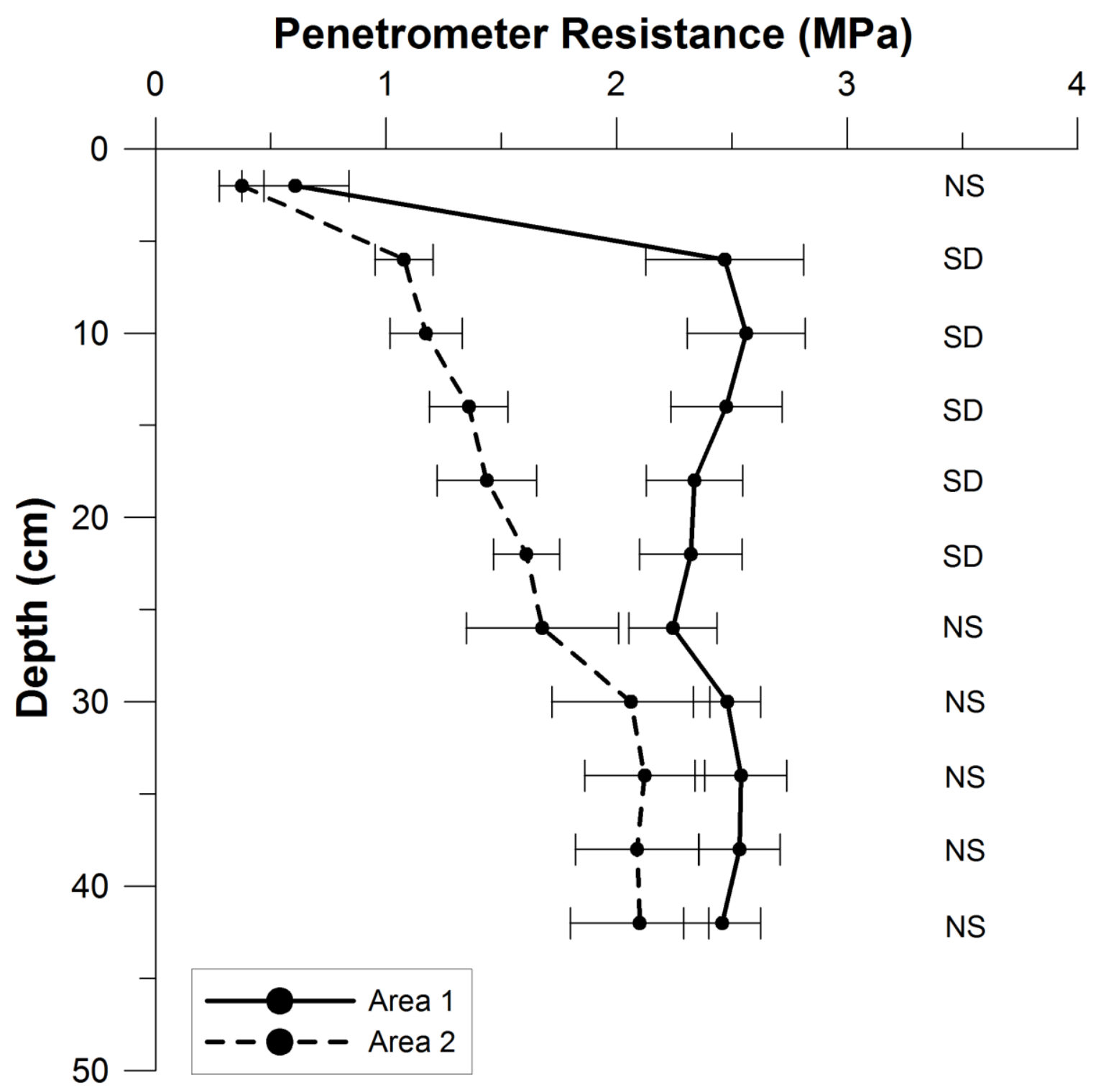

Figure 2 Mean penetrometer resistances for Area 1 and Area 2, with associated standard deviation (error bars) for each data point. Note: SD = significant difference $(\mathrm{P}<0.01)$; NS = not significant 

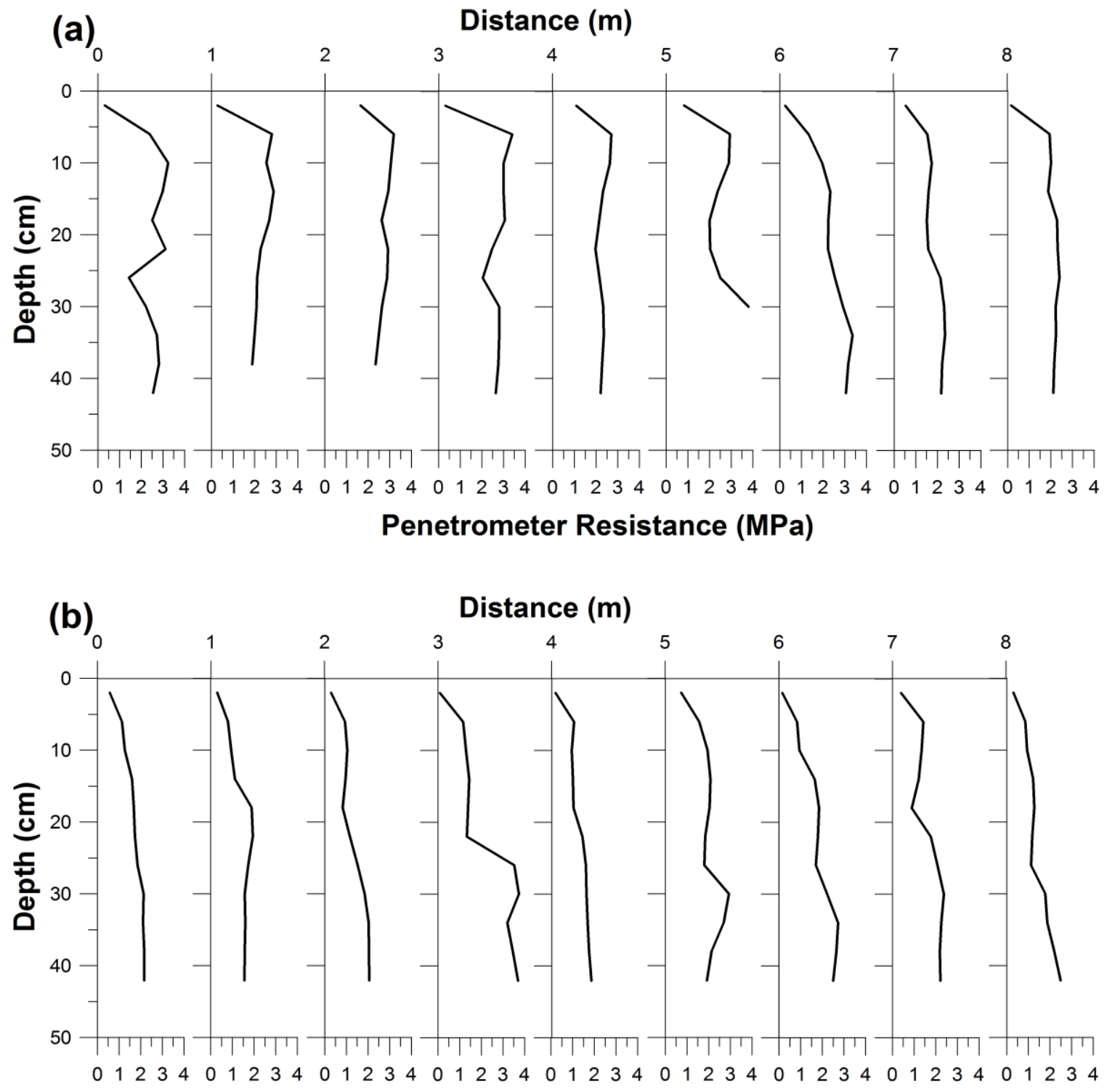

Penetrometer Resistance (MPa)

Figure 3 Linear profile of cone penetrometer soundings for (a) Area 1 and (b) Area 2 
(a)

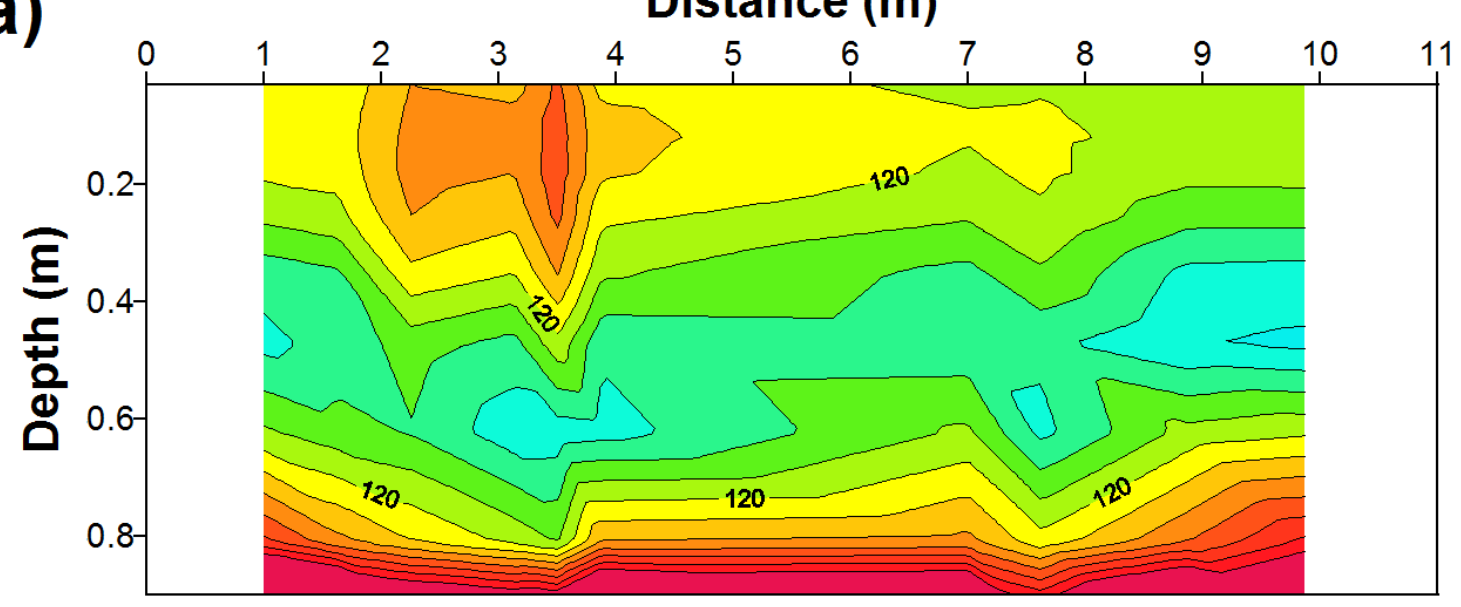

(b)
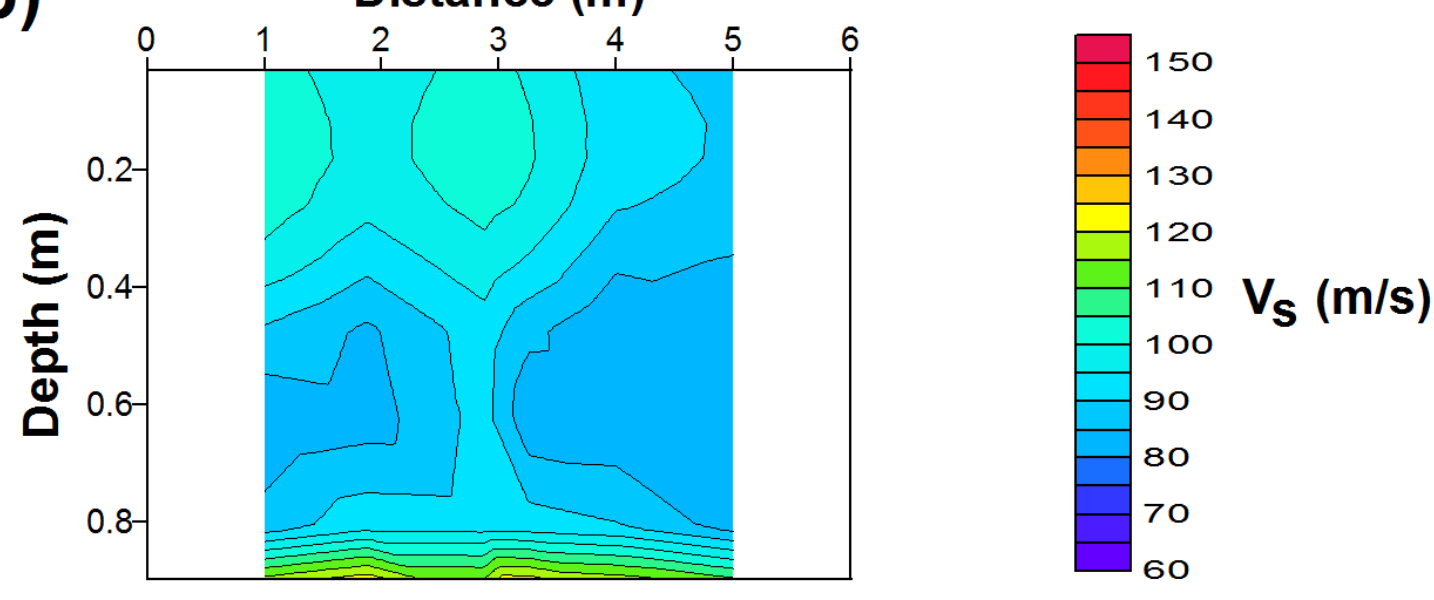

Figure 4 2D inverted shear wave velocity $\left(\mathrm{V}_{\mathrm{s}}\right)$ profile for (a) Area 1 and (b) Area 2 


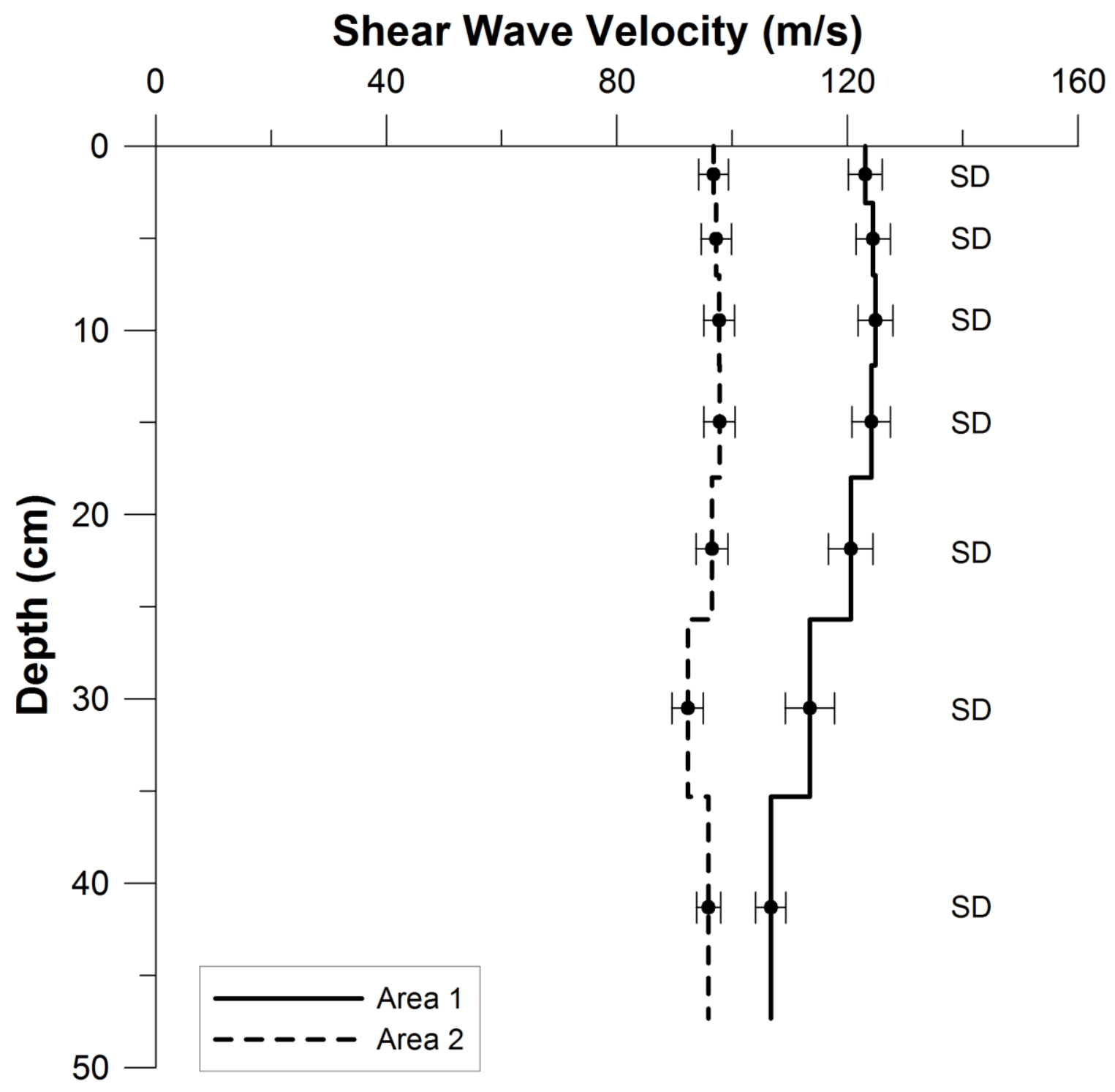

Figure 5 Mean shear wave velocities for Area 1 and Area 2, with associated standard deviation (error bars). Note: $\mathrm{SD}=$ significant difference $(\mathrm{P}<$ $0.01) ; \mathrm{NS}=$ not significant 


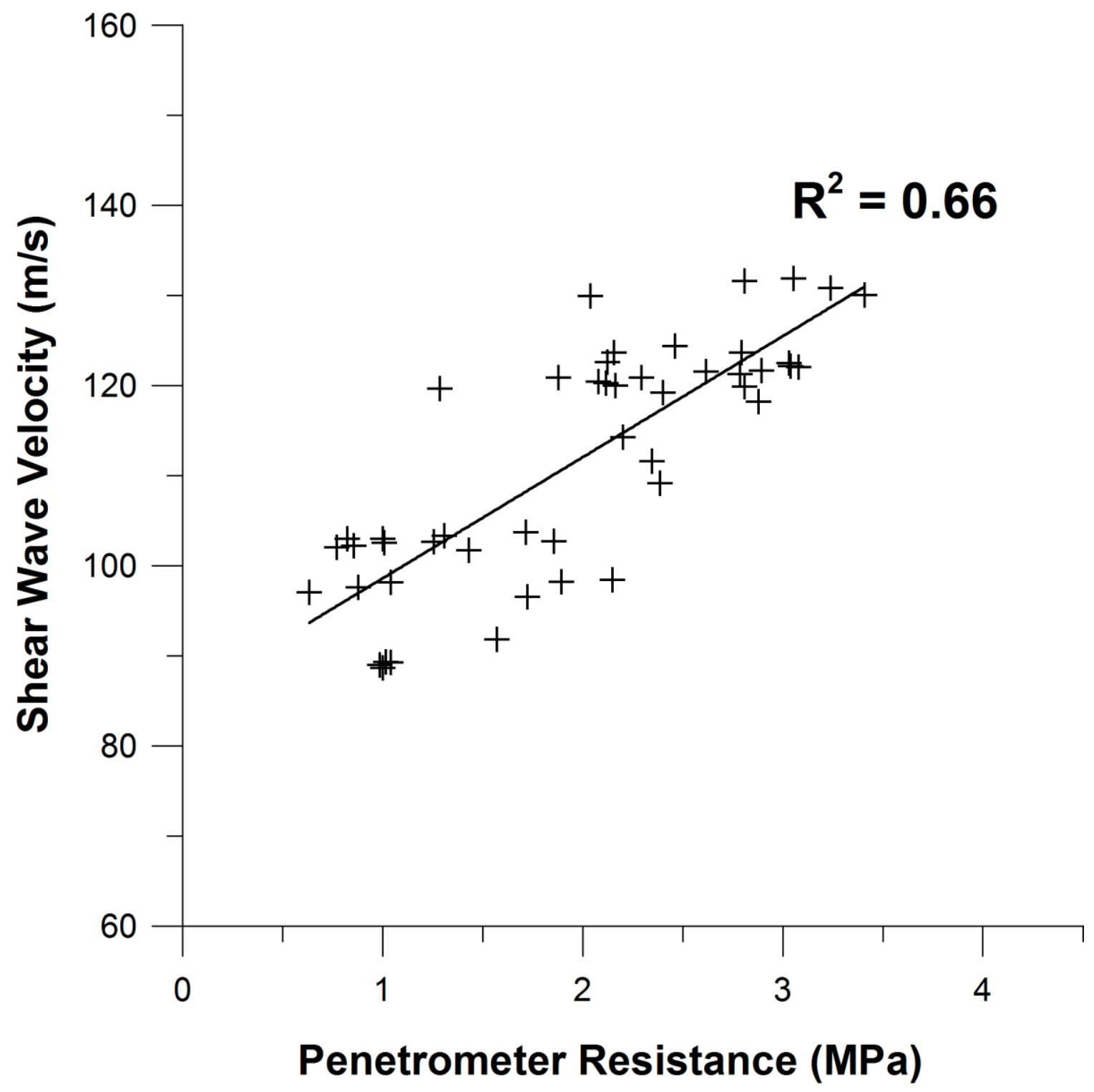

Figure 6 The relationship between $\mathrm{V}_{\mathrm{s}}$ and penetrometer resistance 